\title{
O IDEB E AS POLÍTICAS PÚBLICAS EDUCACIONAIS: estratégias, efeitos e consequências
}

\author{
Givanildo da Silva? \\ Alex Vieira da Silva² \\ Inalda Maria dos Santos 3
}

\section{RESUMO}

O texto objetiva apresentar uma discussão sobre as estratégias, os efeitos e as consequências do Índice de Desenvolvimento da Educação Básica (IDEB) na escola pública brasileira. Como resultados foi possível constatar que: a) O IDEB é, na atualidade, o indutor das políticas educacionais; b) a educação que é desenvolvida com os estudantes, na escola pesquisada, é fragmentada, sendo enfatizadas apenas as disciplinas de Língua Portuguesa e de Matemática; e c) no contexto da escola em análise do município de Messias os profissionais das escolas buscam incentivar os estudantes com premiações para participarem das avaliações, assim como do processo de preparação para esta.

Palavras-chave: IDEB. Políticas Educacionais. Educação Pública.

\section{IDEB AND PUBLIC EDUCATIONAL POLICIES: strategies, effects and consequences}

\begin{abstract}
The text aims to present a discussion about the strategies, effects and consequences of the Basic Education Development Index (IDEB) in the Brazilian public school. As a result it was possible to verify that: a) The IDEB is currently the inducer of policy education; b) the education that is developed with the students, in the researched school, is fragmented, emphasizing only the Portuguese Language and Mathematics subjects; and c) in the context of the school in analysis, from the municipality of Messias, the school professionals seek to encourage students with awards to participate in the evaluations, as well as the process of preparation for this.
\end{abstract}

Keywords: IDEB. Educational Policies. Public education.

\footnotetext{
1 Mestre em Educação. Professor Assistente da Universidade Federal do Vale do São Francisco - Campus Serra da Capivara - São Raimundo Nonato/PI. givanildopedufal@gmail.com

2 Mestre em Educação. Professor da Rede Pública Municipal de Maceió, Maceió/AL. alexpedufal@gmail.com

${ }^{3}$ Doutora em Educação. Professora Adjunta do Centro de Educação e do Programa de Pósgraduação em Educação da Universidade Federal de Alagoas, Maceió/AL. inaldasantos@vol.com.br
} 


\section{EL IDEB Y LAS POLÍTICAS PÚBLICAS EDUCATIVAS: estrategias, efectos y consecuencias}

\section{RESUMEN}

El texto tiene como objetivo presentar una discusión sobre las estrategias, los efectos y las consecuencias del Índice de Desarrollo de la Educación Básica (IDEB) en la escuela pública brasileña. Como resultados fue posible constatar que: a) El IDEB es, en la actualidad, el inductor de las políticas educativa; b) La enseñanza que se desarrolla con los estudiantes en la escuela estudiada, es fragmentado y sólo hizo hincapié en las disciplinas de Lengua portuguesa y Matemáticas; y c) en el contexto de la escuela en análisis del municipio de Mesías los profesionales de las escuelas buscan incentivar a los estudiantes con premios para participar de las evaluaciones, así como del proceso de preparación para ésta.

Palabras clave: IDEB. Políticas Educativas. Educación Pública.

\section{INTRODUÇÃO}

O fracasso da educação americana baseada nos parâmetros do mercado é uma lição que devemos aprender. É preocupante a força das tentativas de implantar esse modelo na educação brasileira. Vemos hoje uma tentativa de economização. O tema da educação passa a ser pautado na grande mídia por economistas, consultores corporativos e de grandes fundações empresariais (AZEVEDO, 2011, p. 14).

As reformas educacionais desenvolvidas na América Latina são frutos das políticas neoliberais implementadas nos países europeus nas décadas de 1970 e 1980. De acordo com Bowles e Gintis (1985, p. 30) "La reforma educativa de la última década no ha marcado um dito em la política social. Por el contratio, ha parecido a todos, incluso a sus más ardientes defensores, que ha sido una prolongación natural de más de um siglo de pensamiento progresista". De um modo geral, as políticas educacionais são vivenciadas na perspectiva de contribuir com uma concepção de sociedade na qual os diferentes setores são responsáveis pelas políticas sociais, a fim de apresentar bons resultados mediante o paradigma político em pauta (BOWLES; GINTIS, 1985).

A defesa pela participação dos diferentes segmentos para a contribuição das problemáticas sociais e educacionais foi uma das estratégias desenvolvidas para o alcance dos objetivos traçados pelas 
políticas neoliberais, destacando a relevância do papel social de cada cidadão para a construção de uma sociedade justa, autônoma e coletiva (SANDER, 1995). Nessa perspectiva, as estratégias planejadas pelos burocratas foram dimensões significativas para a padronização das políticas educacionais e a responsabilização da sociedade civil pelas questões concernentes ao Estado. No conjunto das estratégias desenvolvidas pela reforma educacional, Benno Sander (2005, p. 54) apresenta as principais ações desencadeadas:

Implementação de políticas focalizadas de educação compensatória para grupos de risco, com atenção especial às crianças, às mulheres, às minorias e às populações vulneráveis; estabelecimento de indicadores de avaliação educacional; formação de professores e preparação de administradores educacionais; melhoria da administração educacional, construção da capacidade institucional e participação comunitária; educação para o trabalho e formação vocacional (Grifos nossos).

Nessa lógica, a educação se tornou o principal meio de construção dos ideais da sociedade que se pretendia instituir na América Latina (BOWLES; GINTIS, 1985). Na mesma perspectiva, Benno Sander (2005) cita três importantes instituições para alcançar esses objetivos: a) os governos nacionais; b) as organizações internacionais4; e c) a sociedade civil. Para o autor (p. 58), "os governos nacionais têm sido os atores principais, enquanto as agências internacionais e as entidades da sociedade civil têm desempenhado um papel cooperativo".

Assim, Vitor Paro (2001) destaca que a escola pública foi um dos principais espaços para a disseminação dos objetivos políticos, sociais e educacionais das reformas empreendidas com a finalidade de disseminar os anseios dos reformadores. Para o autor, a qualidade virou sinônimo de produtividade em todas as dimensões educacionais, configurando-se no objetivo central das práticas educativas, via as políticas educacionais, sendo

\footnotetext{
${ }^{4}$ Organização dos Estados Americanos (OEA); Fundo Monetário Internacional (FMI); Banco Interamericano de Desenvolvimento (BID); O Banco Mundial; Comissão Econômica das Nações Unidas para a América Latina e o Caribe (CEPAL); Organização Pan-Americanade Saúde (OPS) e a Organização das Nações Unidas para a Educação, a Ciência e a Cultura (UNESCO) (SANDER, 2005, p. 52).
} 
- Estado o responsável por fiscalizar a produção dos estabelecimentos públicos de ensino, bem como os seus profissionais e estudantes. Na visão de Benno Sander (2005, p. 65), "quanto à implementação de políticas públicas de educação, além de sua formulação adequada, os países precisam preparar-se institucionalmente para responder pela sua efetividade".

O texto objetiva apresentar uma discussão sobre as estratégias, os efeitos e as consequências do Índice de Desenvolvimento da Educação Básica (IDEB) na escola pública brasileira, tendo como aspecto exploratório uma escola da rede pública municipal de Messias, no estado de Alagoas. As políticas educacionais contemporâneas perpassam pela disseminação de resultados quantitativos os quais representam, segundo o Plano Nacional de Educação (2014-2024), a qualidade da educação. Dessa forma, para pensar acerca das políticas educacionais é necessário compreender as tensões, os embates e os conflitos que os profissionais da educação vivenciam no cotidiano das escolas públicas no processo de vivência das práticas educacionais.

A metodologia desenvolvida foi pautada na abordagem qualitativa, por meio das pesquisas bibliográfica e documental, sendo desenvolvidas em uma perspectiva exploratória e interpretativa. Para tanto, foi realizada uma busca nas redes sociais - facebook - de uma escola pública da rede municipal de Messias, no estado de Alagoas, com o propósito de perceber as estratégias que os profissionais desenvolvem para alcançar as metas do IDEB estabelecidas pelo Instituto Nacional de Estudos e Pesquisas Educacionais Anísio Teixeira (INEP).

O texto está estruturado em três partes que se completam, além da introdução e das considerações finais. Na primeira é apresentada uma discussão acerca da política de resultado, tendo o modelo de mercado como paradigma para a educação pública brasileira viabilizada pelas políticas educacionais no contexto das reformas neoliberais; O IDEB e as avaliações em larga escala como instrumentos de vivência das políticas educacionais na escola pública são apresentados na segunda parte; e, por fim, apresentam-se as estratégias desenvolvidas em uma escola da rede 
pública municipal de Messias, no estado de Alagoas, para alcançar as metas do IDEB, por meio das postagens nas redes sociais - facebook.

\section{AS REFORMAS DA EDUCAÇÃO: políticas de resultados e o modelo de mercado}

No final da década de 1970 surgem nos países desenvolvidos atividades que demandam produtividade e eficiência em meio às práticas sociais. A globalização e o desenvolvimento tecnológico são fatores que nortearam os rumos da sociedade e ocasionaram mudanças significativas nas práticas cotidianas das pessoas e das instituições públicas e privadas. $O$ acesso e a aceitação de um novo modelo social significaram rupturas com - que até então estava estabelecido e proporcionou aos países em desenvolvimento e os subdesenvolvidos a tentar se adaptarem a esses novos modelos para ter acesso ao conhecimento, ao comércio e a lógica mercantilista.

De acordo com Bob Lingard (2004, p. 59), "a recente reestruturação de sistemas educacionais pode ser explicada de forma correta recorrendose ao entendimento da globalização". Desse modo, para compreender como se deu o desenvolvimento das reformas nas políticas educacionais, faz-se necessário analisar o processo da globalização e a sua relação com a educação no contexto social.

A partir do fenômeno da globalização, a educação foi tomando novos rumos e consequentemente, a influência desta incidiu em várias consequências, entre elas, políticas educacionais formuladas por empresas multilaterais que visavam à formação dos sujeitos para a atuação no mercado de trabalho, à mão de obra barata, desqualificada, à procura do lucro e, assim, ressignificando o papel social da educação. De acordo com Roger Dale (2004, p. 424):

A "globalização" é frequentemente considerada como representando um inelutável progresso no sentido da homogeneidade cultural, como um conjunto de forças que estão a tornar os estados-nação obsoletos e que pode resultar em algo 
parecido com uma política mundial, e como reflectindo o crescimento irresistível da tecnologia da informação.

Segundo Roger Dale (2004), a globalização está voltada para a homogeneização da cultura em que os estados-nação perdem sua força, sua contribuição na sociedade e, por sua vez, o crescimento da tecnologia da informação colaborou para o fenômeno da globalização e da homogeneização das culturas. Na sua abordagem denominada de "Agenda Globalmente Estruturada para a Educação", Roger Dale (2004, p. 436) destaca que a globalização "é vista como sendo construída através de três conjuntos de atividades relacionadas entre si, económicas, políticas e culturais". Segundo esta mesma abordagem:

A globalização é um conjunto de dispositivos político-económicos para a organização da economia global, conduzido pela necessidade de manter o sistema capitalista, mais do qualquer outro conjunto de valores. A adesão aos seus princípios é veiculada através da pressão económica e da percepção do interesse nacional próprio (DALE, 2004, p. 436).

Roger Dale (2004) destaca a manutenção do sistema capitalista como elemento principal da globalização, pois por meio do capitalismo a economia global cresce acentuadamente. Dessa forma, pode-se inferir que a globalização perpassa por interesses que estão voltados para o crescimento socioeconômico do país. Assim, a educação é o principal setor afetado por este fenômeno, a fim de assegurar que as pessoas inseridas no âmbito escolar, tenham uma formação pautada nos interesses da lógica da economia e do mercado.

Segundo Boaventura de Sousa Santos (2002, p. 27):

A globalização, longe de ser consensual, é um vasto e intenso campo de conflitos entre grupos sociais, Estados e interesses hegemónicos, por um lado, e grupos sociais, Estados e interesses subalternos, por outro; e mesmo no interior do campo hegemónico há divisões mais ou menos significativas.

Nesse sentido, para Boaventura Santos (2002), a globalização é um fenômeno complexo, instituído por conflitos e por interesses de diversos grupos hegemônicos e subalternos da sociedade, configurando-se em um 
campo de lutas, de tensões, de entraves e de dilemas, em que cada grupo tem seus interesses e seus objetivos na estruturação de uma política governamental. Assim, "os processos de globalização mostra-nos que estamos perante um fenómeno multifacetado com dimensões económicas, sociais, políticas, culturais, religiosas e jurídicas interligadas de modo complexo" (SANTOS, 2002, p. 26).

A partir da década de 1990, no Brasil, aconteceram algumas mudanças nas quais ocasionaram um novo modelo de sociedade por meio da concepção política do neoliberalismo. O modelo neoliberal tem como princípio possibilitar que as pessoas tenham autonomia para desenvolverem suas atividades educativas, de saúde e de lazer sem o auxílio do Estado, pois até então havia uma defesa de que o Estado seria o provedor das ações básicas para os cidadãos. Após a implantação das políticas neoliberais no contexto brasileiro, muitas rupturas aconteceram, mudando as ações dos cidadãos no cenário político e social no Brasil.

As práticas neoliberais surgiram no Brasil com intensidade no mandato de Fernando Collor de Melo (1990-1992) e se consolidaram nos mandatos de Fernando Henrique Cardoso (1995-2003) que apresentam à sociedade brasileira uma nova concepção política que tem como principal fator um Estado mínimo com práticas do voluntariado para a sociedade civil e um Estado Avaliador, por meio da implantação de políticas que favorecem aos empresários e ao mercado financeiro.

Após a vivência das práticas neoliberais na sociedade brasileira surgiram diversos fenômenos que evidenciaram as consequências dessa política na esfera social, entre elas destacam-se o "fracasso reiterado das tentativas de estabilização da economia e controle da inflação, retração econômica, aumento das desigualdades, violência urbana e a má qualidade de vida para a população menos favorecida" (BURITY, 2006, p. 72-73). As desigualdades sociais, a falta de oportunidade de emprego, de lazer, de saúde e de educação de boa qualidade para a população foram os aspectos que mais ficaram em evidência, surgindo nas grandes e pequenas cidades as comunidades populares, ficando evidente que a 
maioria da população vive sem as mínimas condições de moradia, de saneamento básico, de iluminação pública de qualidade, de transporte e de lazer.

Em meio às desigualdades visíveis na sociedade brasileira é possível perceber uma pequena fração da população em condições favoráveis tendo suas empresas e seus patrimônios como aspectos que lhes garantem segurança e os bens necessários para ter uma vida digna, diferente da classe trabalhadora que tem sua força de trabalho explorada pelos empresários que formam a burguesia/elite brasileira. Assim, pode-se afirmar que a concepção política neoliberal favorece a classe dominante, pois este paradigma político foi elaborado com princípios favoráveis a classe já favorecida, enquanto que a classe que necessita da intervenção do Estado não tem nenhum auxílio, mesmo que mínimo, para tornar suas vidas menos sofridas (COMBLIM, 1999).

Dessa forma, cabe destacar que o neoliberalismo é uma concepção política que tem em suas raízes uma ideologia dominante, com preceitos reformistas, os quais contribuem para a intensificação das desigualdades social, política, cultural, econômica e educacional. Nesse contexto, Comblim (1999, p. 116-117) afirma:

\begin{abstract}
O neoliberalismo funciona, mas com resultados terríveis nos países do Terceiro Mundo. Em todos os países que experimentaram o sistema, uma pequena elite foi promovida a tal ponto que seu entusiasmo supera as ilusões do Primeiro Mundo. A elite crê que já se acha no Primeiro Mundo, porque goza de todas as vantagens [...] O sistema funciona, porém, com o preço da exclusão da maioria da população e do entusiasmo e do distanciamento crescente entre minoria privilegiada e maioria excludente.
\end{abstract}

As consequências das políticas postas pela concepção do neoliberalismo geram a exclusão, acentuam a desigualdade social e contribuem para que o Estado se exima de seu papel em meio à população que mais necessita das políticas públicas sociais. Em todos os cenários políticos e sociais o Estado passou de provedor para avaliador, apresentando regras e princípios a serem cumpridos pelos atores. No contexto da educação, os profissionais passaram a ser responsáveis pelos 
resultados nas avaliações, por atrair os pais e/ou familiares, juntamente com a comunidade local para que todos pudessem se responsabilizar pelas questões pedagógicas, administrativas e financeiras (FRANÇA, 2005), ficando - Estado alheio ao compromisso de efetivar uma educação pública, inclusiva, igualitária e referenciada socialmente.

As políticas educacionais fazem parte de um processo que estimula o resultado das práticas neoliberais no cenário brasileiro e têm influências de organismos internacionais, os quais objetivam efetivar políticas públicas na tentativa de legitimar os ideais do mercado, por meio da lógica empresarial. Os organismos internacionais foram imprescindíveis no contexto das reformas implementadas, ocasionando novos projetos, novos programas e novas ações desenvolvidos no interior das instituições com caráter reformista, apresentando mudanças nas práticas educacionais da escola pública com objetivos e propostas formuladas com princípios que evidenciem a globalização, a economia, a lógica empresarial e os interesses dos organismos internacionais.

Após o final da segunda guerra mundial alguns acontecimentos marcaram a criação dos organismos internacionais, os quais têm autonomia para influenciar e conduzir as políticas educacionais e direcionar os objetivos para a escola pública, sendo respaldados pelo Estado. Assim, destacam-se: a conferência de Bretton Woods em 1944, evento que consolidou o FMI e o Banco Mundial; a assinatura da carta das Nações Unidas em 1945, no qual culminou na criação da própria ONU e o início das atividades da UNESCO, em 1947 (BENDRATH; GOMES, 2010).

As ações que os organismos internacionais desenvolvem nas escolas públicas são favoráveis aos seus próprios interesses, pois a partir da disseminação das ideologias mercadológicas que estão presentes nos projetos e nas atividades realizadas, a sociedade aprimora esses objetivos, uma vez que as políticas desenvolvidas têm intenções, contribuindo para um paradigma de sociedade, de homem e de cultura. Na década de 1970, a participação do Banco Mundial no ensino básico, no Brasil, era de 1\%, elevando-se para 43\% na década de 1980 (FRANÇA, 2005), atualmente a 
principal instituição internacional que intervém na escola pública brasileira é a UNESCO, por meio de seus projetos em todo território nacional.

Em 1996 foi lançado pelos organismos internacionais um relatório que tem como objetivo apresentar os quatro pilares da educação designados como: aprender a ser, aprender a fazer, aprender a conhecer e aprender a conviver. Esses pilares são, segundo os organismos internacionais, princípios que devem nortear as práticas educacionais, pois são planejados e vivenciados pelos países dos Estados Unidos, França e Espanha tendo resultados positivos (BENDRATH; GOMES, 2010).

Por meio das influências internacionais pode-se refletir sobre aspectos pertinentes para a educação brasileira. A produtividade e a eficiência são princípios propagados pelos organismos internacionais os quais repercutem nas políticas públicas e são aprimoradas pelos educadores e profissionais da educação fazendo com que os estudantes também se insiram nessa lógica de interesses, com intenções bem definidas. As reformas educacionais são exemplos significativos de espaços que dialogam com instituições internacionais concebendo novas posturas de interesse exclusivo dos reformadores. Nessa perspectiva, para Magna França (2005, p. 24):

Nos discursos de políticas educacionais para a década de 1990 dos organismos internacionais, como O BM, CEPAL e UNESCO está presente a visão produtivista, denominada de acumulação de capital humano que concede a Educação como preparação dos indivíduos para o ingresso no mercado de trabalho.

Ainda tomando como base o discurso dos organismos internacionais e a influência do neoliberalismo na educação, Magna França (2005, p. 25) ressalta:

Em meados dos anos de 1990, a orientação do FMl era no sentido de priorizar o ensino fundamental, reduzir os gastos com ensino médio e superior e não adotar, como solução, a destinação de um percentual mais elevado do Produto Interno Bruto - PIB para Educação.

Desse modo, percebe-se que as orientações para novos investimentos estavam fazendo referência apenas ao ensino fundamental, condicionando 
recursos para os projetos e os programas que contemplassem essa etapa escolar. Os municípios, os estados e o Distrito Federal consolidavam as suas políticas por meio dessas orientações. As políticas de Estado para a educação, como o Fundo de Manutenção e Desenvolvimento do Ensino Fundamental e de Valorização do Magistério (FUNDEF), instituído pela Emenda Constitucional n. 14, de setembro de 1996, e regulamentado pela Lei n. ${ }^{\circ}$ 9.424, de 24 de dezembro de 1996, também seguiam os mesmos padrões, repercutindo diretamente na sociedade, apresentando consequências para as demais etapas de escolarização.

Outro aspecto para mencionar é a lógica de interesses que há na atuação dos organismos internacionais ao financiar/emprestar e criar programas educativos para as escolas públicas brasileiras. Enfim, existe uma lógica de poder e de subordinação que acaba gerando riquezas para uns e pobreza para outros. Nas palavras de Silva (2003, p. 298-299):

Nesta política de poder e de edificação de uma outra ordem geopolítica, econômica e social não há espaço para neutralidades, mas, sim, para os interesses. Não é um jogo para amigos e entre amigos. É um jogo de política de poder em que países ricos subjugam países em desenvolvimento. É um jogo em que há o predomínio concreto das nações avançadas, decididas a apropriarse das riquezas sociais e ambientais dos países devedores. O crescimento é do capital e não do desenvolvimento humano e social. As relações são assimétricas, com forte tendência para desconsiderar os meios multilaterais de diálogo entre as nações.

A presença dos organismos internacionais no cenário político educacional tem uma intenção que não é apenas contribuir com o processo de desigualdade social, econômico e cultural da sociedade brasileira, mas sim, de se apossar das riquezas e subjugar nessas forças com ideologias de caráter dominante. Esses objetivos perpassam por todas as dimensões social, cultural, econômica, política e educacional ocasionando rupturas, limites e mudanças para a sociedade (SILVA, 2003).

As reformas da educação brasileira desde a década de 1990 perpassam por instrumentos de avaliação dos resultados (FERREIRA, 2009). Essas foram consolidadas por meio de burocratas que têm a percepção da 
qualidade da educação como sinônimo de resultados, sendo necessário que $o$ Estado programe instrumentos avaliativos para que as escolas, os profissionais e os estudantes possam comprovar o grau de proficiência nas áreas do conhecimento, destacando-se as disciplinas de Língua Portuguesa e de Matemática.

Diversos estudiosos (PARO, 2001; SAVIANI; DOURADO; FILHO, 2014; AZEVEDO, 2014; NARDI, 2014) não compactuam com essa concepção de educação, uma vez que está pautada na lógica do mercado, a qual requer exclusivamente resultados nas diferentes dimensões do processo educacional. Nessa lógica, Paro (2001, p. 37) destaca:

$\mathrm{Na}$ falta de um conceito mais fundamentado de qualidade do ensino, o que acaba prevalecendo é aquele que reforça uma concepção tradicional e conservadora de educação, cuja qualidade é passível de ser medida a partir da quantidade de informações exibida pelos sujeitos presumidamente educados. Esta concepção não apenas predomina nas estatísticas apresentadas pelos organismos governamentais que se propagam por toda a mídia e acabam pautando os assuntos educacionais da imprensa [...], mas se faz presente também em muitos estudos acadêmicos sobre políticas públicas de educação.

A crítica apresentada por Vitor Paro (2001) é propícia, uma vez que há diversos defensores que enfatizam a qualidade da educação por meio dos resultados quantitativos das avaliações em larga escala. Haja vista que o Plano Nacional de Educação (PNE) 2014/2024, Lei n. 13.005 de 2014, na meta 7 apresenta essa perspectiva, direcionando para a educação pública brasileira o compromisso de alcançar bons resultados no IDEB e no Programa Internacional de Avaliação de Estudantes (PISA), até o ano de 2021. A meta 7 do PNE é a que apresenta o maior número de estratégias, isso porque a política indutora dos processos políticos e educacionais perpassam pelos resultados, confirmando a transferência da lógica do mercado para a educação (BOWLES; GINTIS, 1985).

Nesse cenário, é oportuno destacar que a consolidação do Plano Nacional de Educação como Política de Estado foi baseada por meio de tensões e de embates dos diferentes grupos que lutaram para a construção 
de um planejamento educacional pautado em duas grandes perspectivas. De um lado, estavam os defensores da escola pública, democrática, inclusiva e referenciada socialmente. Do outro, encontravam-se os empresários e os defensores das escolas particulares, cujo objetivo era se beneficiar dos recursos da educação pública, mediante a construção das políticas educacionais.

De um modo geral, eis os números a serem alcançados pela educação pública brasileira, segundo a meta 7 do Plano Nacional de Educação (2014-2024):

Quadro I: Médias a serem atingidas pelas escolas públicas no IDEB e no PISA até 2021

\begin{tabular}{|c|c|c|c|c|}
\hline Índice de Desenvolvimento da Educação Básica - IDEB & 2015 & 2017 & 2019 & 2021 \\
\hline Anos iniciais do Ensino Fundamental & 5,2 & 5,5 & 5,7 & 6,0 \\
\hline Anos finais do Ensino Fundamental & 4,7 & 5,0 & 5,2 & 5,5 \\
\hline Ensino Médio & 4,3 & 4,7 & 5,0 & 5,2 \\
\hline Programa InternacionaldeAvaliaçãodeEstudantes - PISA & 2015 & 2018 & 2021 & \\
\hline Média dos resultados em matemática, leitura e ciências & 438 & 455 & 473 & \\
\hline
\end{tabular}

Fonte: Meta 7 do Plano Nacional de Educação (2014-2024), Lei 13.005 de 2014.

Os reformadores da educação buscam igualar os resultados da educação brasileira aos dos países desenvolvidos, sem considerar os conflitos e as diferentes dimensões sociais, culturais e econômicas. Nesse sentido, Bolwes e Gintis (1985, p. 302) enfatizam:

El optimismo de los reformadores no ha recebido recompensa: el problema de la desigualdad no está resuelto. Más bien, su forma ha cambiando. Sin embargo, la estratégia de la reforma no se puede considerar fracasada desde el punto de vista de la clase capitalista. La desviación de los problemas social es hacia o sector estatal desempeña un papel central para la reproducción Del orden capitalista. La forma en que se manifiesta un problema social y el ruedo donde se libran los consecuentes conflictos no son cuestiones de poca importancia. Los conflictos en el sector estatal, por amargos y duraderos que sean, resultan mucho menos amenazadores para el capital, y alteran mucho menos las ganâncias, que los que se dan em la fábrica o la oficina. La natureza clasista de los problemas 
sociales muchas veces queda oculta las manifestaciones de las contradicciones subyacentes son desplazables al sector estatal.

A busca desenfreada por resultados nas políticas educacionais tem sua origem nos países europeus, os quais implantaram uma cultura de padronização dos currículos, do processo educativo e da avaliação da aprendizagem (RAVITCH, 2011). Diane Ravitch (2011), umas das burocratas responsáveis pela reforma da educação nos Estados Unidos da América, avalia que os processos desenvolvidos não serviram para melhorar a qualidade da educação, mas como consequências ficou evidenciado a responsabilização por resultados pelos profissionais da educação, a fragmentação do currículo, a competição entre escolas, turmas e estudantes, a premiação como sinônimo de competência e a implementação da eficiência e da eficácia nas atividades educacionais, semelhante às empresas (RAVITCH, 2011).

Nesse sentido, Diane Ravicth (2011, p. 17-18) apresenta a sua visão sobre as reformas educacionais desenvolvidas nos Estados Unidos da América:

Enquanto folheava as páginas amareladas de minhas anotações, eu comecei a compreender o recente redirecionamento do meu pensamento, minha crescente dúvida a respeito das populares propostas de escolha escolar e responsabilização. Uma vez mais, percebi, eu estava ficando cética diante das panacéias e curas milagrosas. A única diferença era que neste caso eu também havia bebido da fonte que prometia uma cura rápida para problemas intrincados. Eu também havia entrado no barco cheio de bandeiras celebrando o poder de responsabilização, incentivos e mercados. Eu também estava cativada por essas ideias. Elas prometiam um fim à burocracia, a garantia de que crianças pobres não seriam negligenciadas, o empoderamento dos pais pobres, a possibilidade de crianças pobres escaparem de escolas ruins, e o fim da distância de desempenho entre ricos e pobres, negros e brancos.

As reformas desenvolvidas pela autora foram as mesmas que estão em vigor no cenário da escola pública brasileira, descaracterizando o ensino que contemple diversas possibilidades de aprendizagens das crianças, jovens e adultos em detrimento de uma educação direcionando a resolução de testes padronizados. Desse modo, Oliveira (2009) discute que a escola pública está em crise, isso porque as diversas configurações que foram incorporando-se à política organizacional desvirtuaram o objetivo 
primário da educação, ou seja, a socialização dos saberes por meio das experiências individuais e coletivas.

Oliveira (2009) salienta que a escola pública está a serviço do sistema capitalista, o qual requer práticas educacionais que comunguem para a sua permanência. Por isso, é necessário que a lógica do mercado possa ser incorporada no currículo, na avaliação escolar e nas relações pessoais e coletivas. Para Oliveira (2009, p. 31):

\begin{abstract}
Em meio a crise real, constata-se a carência de propostas políticas que realmente tenham força para mudar a situação para melhor. As evidências empíricas parecem pouco eficazes no sentido de apontar possíveis saídas. A situação é complexa, e esperamos, transitória, mas reflete sem dúvida uma contradição maior, estrutural que pode não se resolver nos marcos do capitalismo.
\end{abstract}

Um dos elementos que evidencia a crise da escola pública é a falta de autonomia dos profissionais que vivenciam o processo educacional para construir o próprio currículo, assim como não conseguem desenvolver um trabalho pedagógico direcionado à transformação social da localidade em que a escola está situada, isso porque as propostas educacionais estão pautadas em princípios que configuram apenas os conteúdos padronizados das avaliações em larga escala. Nesse cenário, pode-se afirmar que "a crise da escola parece estar em todo lugar da sociedade. Ela pode ser visualizada quando de forma direta os seus muros já não separam da rua, quando não está mais garantindo o valor do saber ou da certificação" (FERREIRA, 2009, p. 266).

Corroborando com essa proposição, Michael Aplle (2002) afirma que o Estado pode determinar mudanças no currículo, no sistema de avaliação e nas políticas, todas essas mudanças são intencionais, na tentativa de consolidar uma sociedade nos seus moldes. As reformas pautadas na lógica do quase-mercado, segundo Michael Apple (2002, p. 122), desenvolvem estratégias alheias a sua função social:

[...] dentre os perigosos efeitos de uma situação de quase-mercado, situam-se as formas pelas quais as escolas que desejam manter ou ampliar sua posição no mercado "peneiram" para garantir que 
determinados tipos de alunos, com características específicas, sejam aceitos, enquanto outros tipos de alunos são considerados insuficientes. Em algumas escolas, os estereótipos foram reproduzidos de forma que as meninas fossem vistas como mais valiosas, assim como alunos de certas comunidades asiáticas. Crianças afrocaribenhas quase sempre eram consideradas fracassadas.

De um modo geral, as políticas educacionais pautadas nas configurações do mercado e dos resultados geram exclusão, competição e responsabilização dos profissionais da educação. Em síntese, pode-se afirmar que "é um processo complexo, repleto de tendências e impulsos contraditórios" (APPLE, 2001, P. 31), no qual requer conhecimento dos diferentes setores sociais, em especial, dos profissionais que estão no cotidiano das escolas públicas para evitar que essas situações aconteçam com tamanha intensidade.

\section{O IDEB no contexto das avaliações em larga escala nas escolas públicas brasileiras}

As políticas educacionais contemporâneas têm características da reforma gerencial (FREITAS, 2014), sendo essa a referência para o desenvolvimento de mudanças nas quais viabilizem a competividade, a produtividade, a minimização do Estado e a maximização dos participantes na responsabilização das questões políticas, culturais, econômicas e sociais. Nessa visão, as propostas desenvolvidas pelo Estado para a educação são na perspectiva da escola centrada na lógica da empresa, a qual deve produzir e apresentar resultados, sendo as avaliações em larga escala os meios para diagnosticar a eficiência das escolas e das redes de ensino municipais, estaduais e distritais (FREITAS, 2014).

O IDEB foi desenvolvido como índice para a educação básica no contexto de criação do Plano de Desenvolvimento de Educação (PDE), no segundo mandato do presidente Luiz Inácio Lula da Silva (2007-2011), pelo ministro da Educação Fernando Haddad, sendo considerado como a matriz norteadora para a implementação das políticas de governo e de Estado à educação brasileira, apresentado em 15 de março de 2007, tendo sido lançado oficialmente em 24 de abril de 2007 (SAVIANI, 2009). Para Saviani 
(2009, p. 5), "O denominado PDE aparece como um grande guarda-chuva que abriga praticamente todos os programas em desenvolvimento pelo MEC". De acordo com o autor, O PDE é, sem dúvida, a mais ousada, promissora e também polêmica política educacional formulada pelo MEC. Dermeval Saviani $(2009$, p. 1) apresenta que:

O PDE foi saudado como um plano que, finalmente, estaria disposto a enfrentar esse problema, focando prioritariamente os níveis de qualidade do ensino ministrado em todas as escolas de educação básica do país. Mas o Plano mostrou-se bem mais ambicioso, agregando, já na origem, trinta ações que incidem sobre os mais variados aspectos da educação em seus diversos níveis e modalidades.

Desse modo, pode-se compreender que o IDEB é o condutor das políticas educacionais contemporâneas para a educação básica, isso porque todas as referências políticas sobre o contexto local (estado, Distrito Federal, município e/ou escola) o têm como referência. Essa é a principal questão para as mudanças na rotina e na condução pedagógica e administrativa das escolas e das redes de ensino. De acordo com o Ministério da Educação e Cultura (MEC), o IDEB é calculado a partir de dois componentes: a taxa de rendimento escolar (aprovação) e as médias de desempenho nos exames aplicados pelo INEP. Os índices de aprovação são obtidos a partir do Censo Escolar, realizado anualmente pelas escolas.

Ribeiro (2016, p. 100) evidencia que a discussão a respeito do IDEB é importante, pois:

[...] além de envolver uma série de concepções distintas acerca de seu impacto na educação, desdobra-se também em diversas temáticas educacionais tais como: avaliação, currículo, didática, autonomia docente, rankings educacionais e a questão da subjetividade na avaliação. O Ideb tem sido tema não raro na mídia nacional, e tem provocado discussões a respeito de sua confiabilidade e legitimidade para medir a qualidade da educação básica, bem como sua efetiva contribuição para melhorá-la.

Nessa mesma dimensão, estudos acerca do IDEB (RIBEIRO; 2016; GUSMÃO; RIBEIRO, 2016; COSTA-HÜBES, 2013) afirmam que esse mecanismo de avaliação na educação básica gerou mudanças no modo de 
organização das relações pedagógicas. Diferentes perspectivas são vivenciadas na intenção de alcançar os índices projetados pelo INEP. Os estudos evidenciam, ainda, a relevância de uma política de avaliação na qual destaque todos os processos formativos, bem como salienta a construção de uma educação integral, a qual possibilite a ênfase nas diversas áreas do currículo e nas múltiplas práticas formativas, diferentemente da atual.

Para Freitas (2014), as avaliações em larga escala têm caráter de padronização das práticas pedagógicas, tendo como foco dessas políticas os resultados e a presença dos empresários nas atividades pedagógicas. Segundo o autor, a consolidação de módulos, de apostilas e de sistemas é marcante na atualidade com objetivo de proporcionar treinamentos para os estudantes nas avaliações. As consultorias, as empresas que preparam materiais pedagógicos e as diferentes estratégias vivenciadas pelas escolas possibilitam inferir que diferentes interesses estão presentes nas escolas públicas, controlando as práticas educativas e possibilitando mecanismos de centralização nas avaliações e não no processo de aprendizagem. Freitas (2014, p. 1093) menciona:

$\mathrm{Na}$ atual disputa pela escola, os reformadores empresariais da educação ampliaram a função da avaliação externa e deram a ela um papel central na indução da padronização como forma de permitir o fortalecimento do controle não só sobre a cultura escolar, mas sobre as outras categorias do processo pedagógico, pelas quais se irradiam os efeitos da avaliação, definindo o dia a dia da escola (Grifos do autor).

As ações desenvolvidas pela política educacional, mediante as configurações das avaliações em larga escala, estão presentes e visíveis no cenário da escola pública, especialmente, quando se evidencia umas áreas do conhecimento em detrimento de outras, gerando uma segregação de saberes, viabilizado pelas exigências das avaliações. A exclusão de saberes no currículo empobrece $\circ$ processo pedagógico e os conhecimentos acumulados ao longo dos tempos, gerando uma proposição de 
desigualdade e um conflito ideológico entre a educação dos filhos da classe trabalhadora em relação aos filhos da elite brasileira.

Outro fator de tensão nesse processo é a neutralidade da autonomia do professor, uma vez que os objetivos educacionais e o planejamento do docente são objetos da didática do profissional da educação que não estão tendo visibilidade nas políticas de avaliações em larga escala (FREITAS, 2014). Para o autor, é importante refletir sobre estas questões, pois possibilitam visualizar a sociedade que queremos formar, assim como a concepção de escola, de homem e de educação que as políticas públicas educacionais estão desenvolvendo. Nessa dimensão é possível afirmar que o objetivo maior dos burocratas da educação é quantificação do saber, assim como os dados quantitativos e suas repercussões no cenário nacional e internacional (FREITAS, 2014).

As leituras de Freitas (2014) e de Ribeiro (2016) evidenciam que as políticas educacionais desenvolvidas para a construção do IDEB são propícias ao empobrecimento da educação pública democrática, inclusiva e de boa qualidade, uma vez que a exclusão de saberes e de alguns estudantes se dá no contexto de vivência dos amontoados de testes e treinamentos para a realização das provas. Outro fator refere-se à dimensão da pressão aos professores por resultados satisfatórios, "ou quando o seu salário está associado ao sucesso da criança nas provas da avaliação externa, ela interfere irremediavelmente nesta relação e sela o destino da criança" (FREITAS, 2014, p. 1097).

\section{A busca por resultados: estratégias, efeitos e consequências em uma escola no município de Messias/AL}

O município de Messias fica localizado na zona da mata alagoana, há $30 \mathrm{~km}$ da capital do estado. Segundo o Instituto Brasileiro de Geografia e Estatística (IBGE), há aproximadamente18 mil habitantes. A rede pública municipal de educação local oferta a educação infantil, o ensino fundamental I e II e a educação de jovens e adultos. No município há uma escola estadual, a qual atende a demanda do ensino médio. 
Em meio às escolas da localidade, uma se destaca pelo seu tamanho e o número de alunos. Desse modo, essa foi a escola foco do estudo. $O$ critério da escolha se deu pela demanda de estudantes que a escola atende e por ser a mais antiga do município. Seguem algumas informações:

Quadro 2: Quantidade de estudantes da escola X no ano letivo de 2016

\begin{tabular}{|l|c|}
\hline Matrícula por ano & Quantidade de estudantes \\
\hline $1^{\circ}$ ano do EF & 39 \\
\hline $2^{\circ}$ ano do EF & 46 \\
\hline $3^{\circ}$ ano do EF & 55 \\
\hline $4^{\circ}$ ano do EF & 51 \\
\hline $5^{\circ}$ ano do EF & 67 \\
\hline $6^{\circ}$ ano do EF & 454 \\
\hline $7^{\circ}$ ano do EF & 352 \\
\hline $8^{\circ}$ ano do EF & 393 \\
\hline $9^{\circ}$ ano do EF & 283 \\
\hline TOTAL & 1740 \\
\hline
\end{tabular}

Fonte: Disponível em: <http://qedu.org.br >, acesso em 27 de dez. de 2017, às 10:20 h.

De um modo geral, a escola apresenta boas condições para o desenvolvimento das atividades pedagógica, administrativa e financeira. Em relação às dependências e equipamentos, pode-se constatar que a escola possui:

Quadro 3: Dependências e equipamentos da escola X no ano letivo de 2016

\begin{tabular}{|l|c|l|c|}
\hline Sanitários & S & Sala para os professores & S \\
\hline Biblioteca & S & Sala de atendimento especial & S \\
\hline Cozinha & S & Aparelho de DVD & S \\
\hline Laboratório de Informática & S & TV & N \\
\hline Laboratório de Ciências & N & Datashow & S \\
\hline Sala de Leitura & S & Impressora & S \\
\hline Quadra de Esportes & S & Copiadora & S \\
\hline Sala para diretoria & S & Internet & S \\
\hline
\end{tabular}

Fonte: Disponível em:<http://qedu.org.br>, acesso em 27 de dez. de 2017, às 10:46 h.

Todas as escolas da rede pública municipal de Messias divulgam suas atividades desenvolvidas nas redes sociais, sendo o facebook o instrumento para essa ação. Assim, por meio desse mecanismo de comunicação foi realizada uma pesquisa de caráter exploratória para procurar postagens 
que pudessem contribuir na interpretação das estratégias vivenciadas para alcançar as metas do IDEB. Foram escolhidas quatro postagens que mais se aproximam das discussões ancoradas pelos pesquisadores e estudiosos da política educacional. Seguem as postagens:

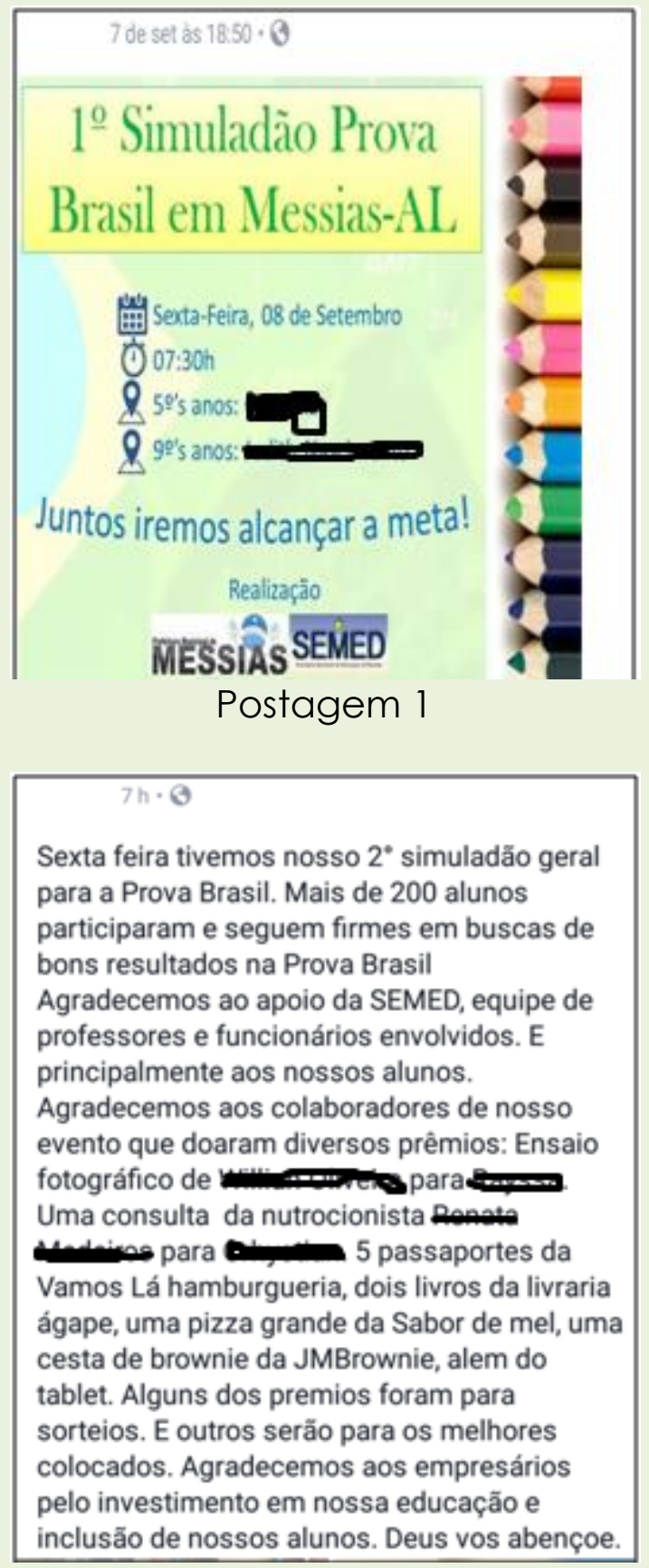

Postagem 3

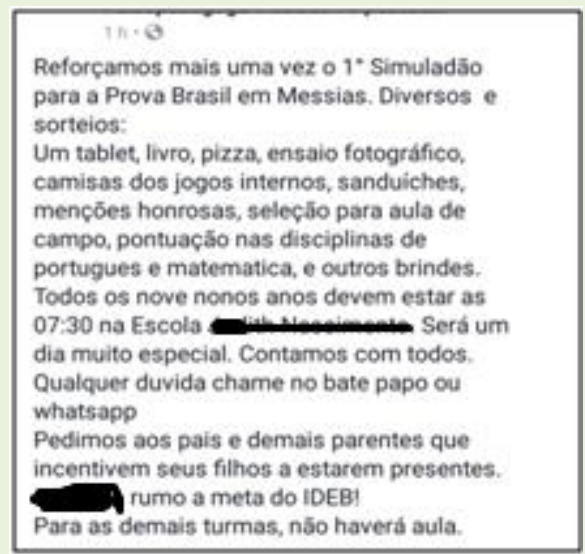

Postagem 2
Amanhã teremos mais um grande evento em
nossa educação. Com sorteio de brindes como
pizza, cesta de chocolate, livros, entre outros. E
com destaque para o prêmio de um tablet para
o aluno que conseguir a melhor nota.
Contamos com todos os alunos dos $5^{\prime \circ} \mathrm{s}$ anos
no $\mathrm{G}$. Todos pela
manhã as $07: 30$. Para as demais turmas, não
haverá aula. Postagem 4

As postagens destacadas são algumas exemplificações das estratégias que as escolas públicas desenvolvem para alcançar as metas que o IDEB projeta. No contexto da rede pública municipal de Messias, uma 
questão recorrente é a realização de simulados para os alunos que desenvolverão a Prova Brasil ( $5^{\circ}$ e $9^{\circ}$ anos), programado pela Secretaria Municipal de Educação (SEMED) e pelas próprias escolas. As quatro postagens evidenciam essa característica, com um teor mais indutivo para a questão da premiação e da exposição dos estudantes que se destacam nos testes.

A rede pública municipal de Messias obteve em 2015 média 5.0 no IDEB, já a escola em análise 3,9, não alcançando a meta projetada. Os quadros abaixo mostram os resultados e as metas do município de Messias e da referida escola:

Quadro 4: Resultados e Metas do IDEB do município de Messias, Alagoas

\begin{tabular}{|c|c|c|c|c|c|c|c|c|c|c|c|c|c|c|}
\hline & \multicolumn{6}{|c|}{ Ideb Observado } & \multicolumn{8}{|c|}{ Meta s Projgtadas } \\
\hline Municiplo = & $2005 \div$ & $2007 \div$ & $2000=$ & $2011=$ & $2013=$ & $2015^{*}$ & $2007 *$ & $2009=$ & $2011=$ & $2013=$ & $2015 \div$ & $2017 \%$ & $2019=$ & 2021 \\
\hline Messtas & 3.2 & 32 & 40 & 39 & 4.4 & 50 & 3.3 & 3.6 & 4.0 & 4.3 & 4.6 & 49 & 5.2 & 5.5 \\
\hline
\end{tabular}

Fonte: <http://ideb.inep.gov.br/resultado/resultado/resultado.seam?cid=1991379>, acesso em 27 de dez. de 2017, às 11:04 h.

Quadro 5: Resultados e Metas do IDEB da escola X do município de Messias, Alagoas

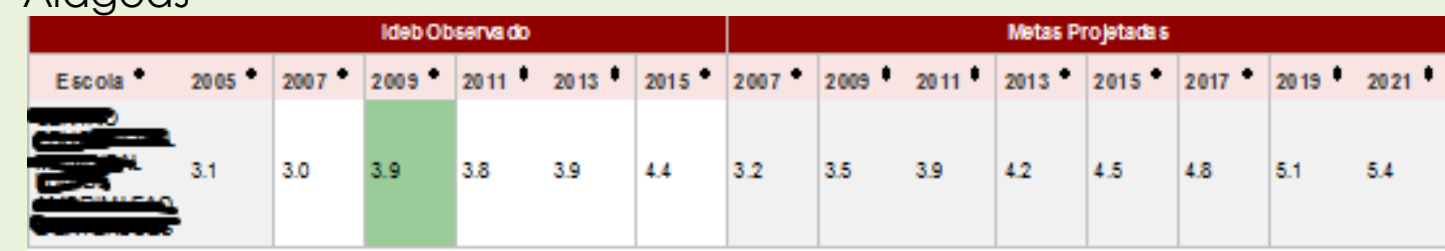

Fonte:

Disponível

em:

$<$ http://ideb.inep.gov.br/resultado/resultado/resultado.seam? $\mathrm{cid}=1991628$, acesso em 27 de dez. de 2017, às 11:26 h.

Diante da problemática de não alcançar as metas projetadas, a escola pesquisada desenvolveu estratégias para que tanto os profissionais da educação quanto os estudantes pudessem se envolver para o desenvolvimento da Prova Brasil em uma perspectiva de divulgação de resultados para a comunidade interna e externa. Outro fator relevante é a questão da premiação, ainda durante a realização dos simulados, como sinalizados nas postagens, haja vista que os prêmios e a concorrência entre os estudantes podem ser uma estratégia significativa para 0 alcance das metas projetadas. Nessa lógica, a sala de aula e a escola tornam-se instrumentos para a competição, a eficiência e a eficácia, assemelhando-se 
às empresas que têm metas para serem cumpridas. Freitas (2014, p. 1099) apresenta críticas a esse paradigma, uma vez que:

A sala de aula e a escola não são uma linha de produção sobre a qual pode-se cravar uma série de relógios que indicam se a produção está sendo feita segundo as metas ou se está havendo algum "desvio". Muito diferente disso, a escola e a sala de aula se assemelham a uma rede de relações multilaterais que não deve sofrer interferências não planejadas de fora, e na qual as ações devem ser acordadas, ou seja, negociadas entre os variados participantes do processo.

É importante destacar que a rede municipal de Messias e a escola em questão buscaram parcerias com diferentes segmentos do município para conseguir a premiação para os estudantes. Foram empresários, comerciantes e outros segmentos sociais que contribuíram para a realização dessa atividade. No âmbito dos trabalhos pedagógicos desenvolvidos nas escolas, todos os profissionais se envolvem para que os seus estudantes tenham bons resultados e sejam premiados. Dessa forma, "O diretor da escola se transforma em um animador que controla metas previamente "comunicadas aos colaboradores" com processos bem definidos e controlados "passo a passo", de forma a "premiar, punir e corrigir desvios" (FREITAS, 2014, p. 1103).

Em relação aos demais profissionais, Freitas (2014, p. 1103) salienta que "opera-se a mesma desqualificação que ocorre no interior dos processos produtivos com a introdução de novas tecnologias e com os controles gerenciais, ou seja, os profissionais vão tornando-se facilmente substituíveis e, portanto, aligeira-se a sua própria formação profissional".

As reflexões que podem ser desenvolvidas por meio das postagens apresentadas é que a educação pública na escola em questão da rede municipal de Messias está trabalhando na perspectiva da lógica capitalista e empresarial, consolidando os objetivos dos grupos empresariais. Sem falar na fragmentação dos conhecimentos, isso porque as disciplinas em destaques para esse processo são Língua Portuguesa e Matemática, como vivenciados nos simulados. Ravitch (2011, p. 94) destaca que "os escores em leitura e matemática se tornaram o tudo ou nada da educação pública da 
terceira à oitava série. A leitura e a matemática eram as únicas matérias que contavam para a responsabilização institucional, do Estado e da federação".

A competição e a premiação também se destacam como princípios geradores de posturas individualistas, advindos do modelo neoliberal, e pautados pelo anseio de se destacar para ganhar o prêmio. No entanto, para atingir essa finalidade é necessário que os estudantes se destaquem e tirem boas notas nos testes elaborados pela SEMED. Na visão de Michael Apple (2001, p. 35), "em um tempo de competição internacional severa, as escolas estão falhando e, produzir uma força de trabalho suficientemente habilitada, adaptável, flexível". Ao desenvolver as estratégias de premiação e de competição entre os estudantes, consolida-se a gestão gerencial e mercadológica, com a finalidade de responder aos ditames do capital.

A crise da escola pública está em pauta e as políticas educacionais consolidam essa crise quando salienta que as escolas necessitam apresentar bons resultados quantitativos para medir a qualidade da educação. Questões como essas proporcionam que as redes de ensino, as escolas e os seus profissionais respondam positivamente a esse paradigma, fragmentando os processos formativos e a oferta de uma educação na qual valorize saberes, experiências e culturas. No entanto, é necessário compreender o sistema educacional como resultado das contradições do sistema capitalista, o qual também reflete nas diversas esferas sociais.

\section{CONSIDERAÇÕES FINAIS}

As políticas públicas educacionais são configuradas no campo das disputas, das tensões e dos conflitos, por meio de diferentes interesses que têm concepções e proposições distintas na efetivação da concepção de sociedade e na construção de um espaço de inclusão ou exclusão. Nesse sentido, a educação é um dos campos sociais propícios para a concretização desses ideais, os quais repercutem diretamente no trabalho docente, no processo de ensino e aprendizagem, bem como nas avaliações educacionais. 
Nessa lógica, o IDEB, em nosso país, tornou-se o principal diagnóstico técnico-quantitativo da educação básica, no quesito qualidade. Porém, ele é frágil e ainda não é capaz de contar tudo. Não é capaz de contar as condições de trabalho, de ensino e de aprendizagem que os professores e gestores operam, nem é capaz de compreender de fato a qualidade do ensino da instituição, dadas as suas limitações (RIBEIRO, 2016). De um modo geral, mesmo sendo o condutor das políticas contemporâneas, esse instrumento é injusto, excludente e não responde aos anseios de uma educação pública referenciada socialmente.

Da forma como as reformas pautaram as políticas educacionais, pode-se analisar que essas se tornaram espaços para padronizar o ensino, quantificar a aprendizagem e avaliar os atores envolvidos no processo pedagógico. A lógica empresarial está presente nas ações educativas e possibilitou que a escola se transformasse um lugar vazio e sem sentido, com ênfase na meritocracia, na competividade, na eficácia e na eficiência.

No entanto, é necessário destacar que as escolas são instituições sociais, filhas do seu tempo, logo, estão inseridas na lógica capitalistas, as quais reverberam nas políticas educacionais e consequentemente no chão da escola pública, repercutindo em suas práticas e propostas educativas. Assim, pode-se perceber as contradições da função social da escola, quando necessita responder positivamente aos ditames do sistema vigente.

Em relação às estratégias desenvolvidas pela escola da rede pública municipal de Messias, percebe-se que essa está trabalhando na mesma perspectiva defendida nas políticas neoliberais e gerenciais, incentivando a competição entre os profissionais e os estudantes, mediante a oferta de premiação. Assim, o paradigma educacional que está pautado nas práticas educativas é similar ao das empresas, sendo necessário que todos os envolvidos contribuam para alcançar os objetivos traçados nas políticas educacionais.

Essas ações comprometem a qualidade da educação e contribuem para a exclusão dos estudantes com mais dificuldades, bem como apresenta uma falsa concepção de qualidade para a sociedade. É 
necessário que se construam novos horizontes de avaliação da educação, apresentando os desafios cotidianos de cada estabelecimento de ensino, no qual tenham como construtores das políticas locais os profissionais e a comunidade na qual a escola está presente. É preciso romper com a lógica do capital e viabilizar estratégias de superação da desigualdade educacional; superar as atuais concepções de educação e de avaliação para que toda a sociedade possa planejar e construir um processo escolar pautado na justiça, na igualdade e na coletividade. Eis, portanto, o desafio!

\section{REFERÊNCIAS}

APPLE, M. W. Podem as pedagogias críticas sustar as políticas de direita? Cadernos de Pesquisa, São Paulo, n. 116, p. 107-142, jul./2002.

APPLE, M. W. Política cultural e educação. São Paulo: Cortez, 2001. Trad. Maria José do Amaral Ferreira.

AZEVEDO, J. M. L. de. Plano Nacional de Educação e Planejamento: a questão da qualidade da educação básica. Revista Retratos da Escola. Brasília, v. 8, n. 15, p. 265-280. Jul./dez. 2014.

AZEVEDO, J. C. de. Apresentação da obra Vida e morte do grande sistema escolar americano: como os testes padronizados e o modelo de mercado ameaçam a educação (Diane Ravitch). Porto Alegre: Sulina, 201 1. Trad. Marcelo Duarte. p. 11-14.

BENDRATH, E. A.; GOMES, A. A. Estado, Políticas públicas e organismos internacionais: a educação no foco do debate. InterMeio: revista do Programa de Pós-Graduação em Educação, Campo Grande, MS, v.16, n. 32, p. 157-171, jul./dez. 2010.

BOWLES, S.; GINTIS, H. La instrucción escolar enla América Capitalista: la reforma educativa y lascontradicciones de la vida econômica. Madrid: S. L. Polígono Igarsa, 1985.

BRASIL. Lei n 13.005, de 25 junho de 2014: Plano Nacional de Educação. Brasilia, 2014.

BURITY, J. A. Redes, parcerias e participação religiosa nas políticas sociais no Brasil. Recife: Fundação Joaquim Nabuco, Massangana, 2006.

COMBLIM, J. O neoliberalismo: ideologia dominante na virada do século. Petrópolis: Vozes, 1999. 
COSTA-HÜBES, T. da C. Formação continuada para professores da educação básica nos anos iniciais: ações voltadas para municípios com baixo ldeb.

Revista Brasileira de Estudos pedagógicos, Brasília, v. 94, n. 237, p. 501-523, maio/ago. 2013.

DALE, R. Globalização e educação: demonstrando a existência de uma "Cultura Educacional Mundial Comum" ou localizando uma "Agenda Globalmente Estruturada para a Educação"?. Revista Educação e Sociedade, Campinas, v. 25, n. 87, p. 423-460, ago. 2004.

FERREIRA, E. B. Políticas educativas no Brasil em tempo de crise. In: FERREIRA, E. B.; OLIVEIRA, D. A. (Orgs.). Crise da escola e políticas educativas. Belo Horizonte: Autêntica, 2009.

FRANÇA, M. Gestão e financiamento da educaçãoo que mudou na escola?: programa dinheiro direto na escola. FUNDEF. Natal, RN - Editora UFRN, 2005.

FREITAS, L. C. de. Os reformadores empresariais da educação e a disputa pelo controle do processo pedagógico da escola. Revista Educação e Sociedade, Campinas, v. 35, n. 129, p. 1085/1114, out./dez. 2014.

GUSMÃO, J. B. de; RIBEIRO, V. M. A política educacional do Acre e os resultados do Ideb. Revista Brasileira de Estudos pedagógicos, Brasília, v. 97, n. 247, p. 472-489, set./dez. 2016.

LINGARD, B. É e não é: Globalização vernacular, Política e Reestruturação Educacional. In: BURBULES, N. C.; TORRES, C. A. (Org.). Globalização e educação: perspectivas críticas. Porto Alegre: Artmed, 2004.

NARDI, E. L. Políticas de responsabilização e PNE: tendências, ensaios e possibilidades. Revista Retratos da Escola. Brasília, v. 8, n. 15, p. 281-292. Jul./dez. 2014.

OLIVEIRA, D. A. Política educativa, crise da escola e a promoção de justiça social. In: FERREIRA, E. B.; OLIVEIRA, D. A. (Orgs.). Crise da escola e políticas educativas. Belo Horizonte: Autêntica, 2009.

PARO, V. H. Escritos sobre educação. São Paulo: Xamã, 2001.

RAVITCH, D. Vida e morte do grande sistema escolar americano: como os testes padronizados e o modelo de mercado ameaçam a educação. Porto Alegre: Sulina, 2011 . Trad. Marcelo Duarte.

RIBEIRO, M. de P. Gestão escolar pública: refém do Ideb? Dialogia, São Paulo, n. 24, p. 99-112, jul./dez. 2016. 
SANDER, B. Gestão da educação Na América Latina: construção e reconstrução do conhecimento. Campinas, SP: Autores Associados, 1995.

SANDER, B. Políticas públicas e gestão democrática da educação. Brasília: Liber Livro Editora, 2005.

SANTOS, B. de S. Os processos de globalização. SANTOS, Boaventura de Sousa. A Globalização e as Ciências Sociais. São Paulo: Cortez, 2002.

SAVIANI, D. PDE - Plano de Desenvolvimento da Educação: análise crítica da política do MEC. Campinas, SP: Autores Associados, 2009.

SAVIANI, D.; DOURADO, L. F.; FILHO, H. A. Entrevista. Revista Retratos da Escola. Brasília, v. 8, n. 15, p. 231-246. Jul./dez. 2014.

SILVA, M. A. Do Projeto Político do Banco Mundial ao Projeto PolíticoPedagógico da Escola Pública Brasileira. Caderno Cedes, Campinas, v. 23, n. 61, p. 283-301, dezembro 2003.

Recebido em: 30 de janeiro de 2018 Aprovado em: 31 de outubro 2018 